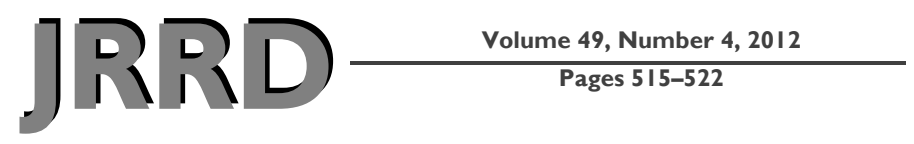

\title{
Extraterritorial temperature pain threshold abnormalities in subjects with healed thermal injury
}

\author{
Tanya Z. Fischer, MD, PhD; ${ }^{*}$ Stephen G. Waxman, MD, PhD \\ Department of Neurology and Center for Neuroscience and Regeneration Research, Yale University School of Medicine, \\ New Haven, CT; Rehabilitation Research Center, Department of Veterans Affairs Connecticut Healthcare System, West \\ Haven, CT
}

\begin{abstract}
Approximately 1.25 million individuals sustain burn injuries annually in the United States. Pain is frequent in patients with burn injuries and is often refractory to pharmacotherapy. We report quantitative sensory data from five subjects who sustained external thermal injuries to their limb(s) 8 weeks to 11 years previously, demonstrating reduced thermal pain thresholds in regions outside the burn injury zone, including contralateral limbs. Warm and cold detection thresholds were not significantly different from controls. These results complement data from animal models that demonstrate that allodynia can develop contralateral to a focal burn injury as a result of changes within the spinal cord and suggest that systemic or central mechanisms contribute to pain after burn injury.
\end{abstract}

Key words: allodynia, burn, extraterritorial, hyperalgesia, neuropathic pain, pain, pain threshold, sensitivity, sensory assessment, thermal injury.

\section{INTRODUCTION}

Pain is the most frequent complaint of patients with burn injuries, and in many instances it is refractory to currently available therapies [1]. Moreover, burn pain is often undertreated [2-3], can be chronic [4-5], and has a long-term impact on quality of life [6-7]. Although there have been some human studies evaluating cutaneous pain in burned patients [4-5], the exact nature of and mechanisms contributing to these patients' chronic pain is not fully understood.
Evidence for the extraterritorial spread of pain, i.e., enlargement of the area of pain so that pain is felt outside of the area corresponding to the initial injury, has been described following a unilateral injury in animal models. For example, allodynia initially develops in the territory innervated by the injured sciatic nerve in a rat model of chronic constriction nerve injury but subsequently extends to the territory of the uninjured saphenous nerve [8]. In an animal model of mild hindpaw thermal injury, primary hyperalgesia developed in the region of the injury and was accompanied by secondary tactile allodynia in an uninjured area of the paw [9]. Similar findings were seen in a human model of mild, nonblistering thermal injury [10].

It has been suggested that burn injury may trigger an immune or inflammatory response that contributes to hyperalgesia, which can persist after burns are healed [11-14]. Activation of p38 mitogen-activated protein kinase within spinal microglia has been demonstrated in a first-degree burn injury model, and evidence suggests

\footnotetext{
Abbreviations: QST = quantitative thermal sensory testing, SEM = standard error of the mean, VAS = visual analog scale.

*Address all correspondence to Tanya Z. Fischer, MD, PhD; Rehabilitation Research Center, VA Connecticut Healthcare System, 950 Campbell Avenue, Building 34, West Haven, CT 06516; 203-937-3802; fax: 203-937-3801. Email: tanya.fischer@yale.edu http://dx.doi.org/10.1682/JRRD.2011.04.0071
} 
that these glial cells can contribute to the pathogenesis of pain [15]. In a second-degree burn injury model in the rat, a unilateral burn injury produced long-lasting allodynia with eventual spread to the contralateral limb [16]. These animals also demonstrated a sequential pattern of ipsilateral and subsequent contralateral dorsal horn neuron hyperexcitability and microglial activation associated with increased phosphorylated-p38 expression [16]. These observations suggest that central or systemic mechanisms contribute to long-lasting pain following peripheral burn injury. We sought to test the hypothesis that extraterritorial changes in pain thresholds, including contralateral pain-like changes, occur in humans following a focal thermal injury.

\section{METHODS}

\section{Subjects}

We studied five unrelated subjects who had sustained a blistering thermal injury and eight age-matched nondisabled control volunteers. Subjects with a history of a thermal burn on an external body area (limb(s), trunk, and/or face) that was completely healed at the time of testing were eligible for enrollment into the study. Subjects sustaining internal burn injuries were not eligible. Potential subjects were required to be in stable health, have intact cognition, and be without any other cause for chronic or neuropathic pain. Subjects with average daily pain (at time of injury) of at least moderate severity, which was defined as $\geq 2$ on a $0-10$ numerical scale on which 0 meant "no pain" and 10 meant the "worst pain imaginable," were studied.

Each subject with a thermal injury completed an intake questionnaire and filled out a pain map. Sensory assessment was carried out at (1) a site located $5 \mathrm{~cm}$ proximal to the proximal edge of the burned area (Figure 1); (2) in the same location on the contralateral region in the four subjects with unilateral burns or $5 \mathrm{~cm}$ proximal to the proximal edge of the burn on both sides in the subject with bilateral burns; and (3) on a third separate body area, specifically the dorsum on the foot. None of the study subjects were taking any medications targeting any form of pain at the time of study.

\section{Sensory Assessment}

Each subject completed an intake questionnaire that included a description of the location of the injury, how

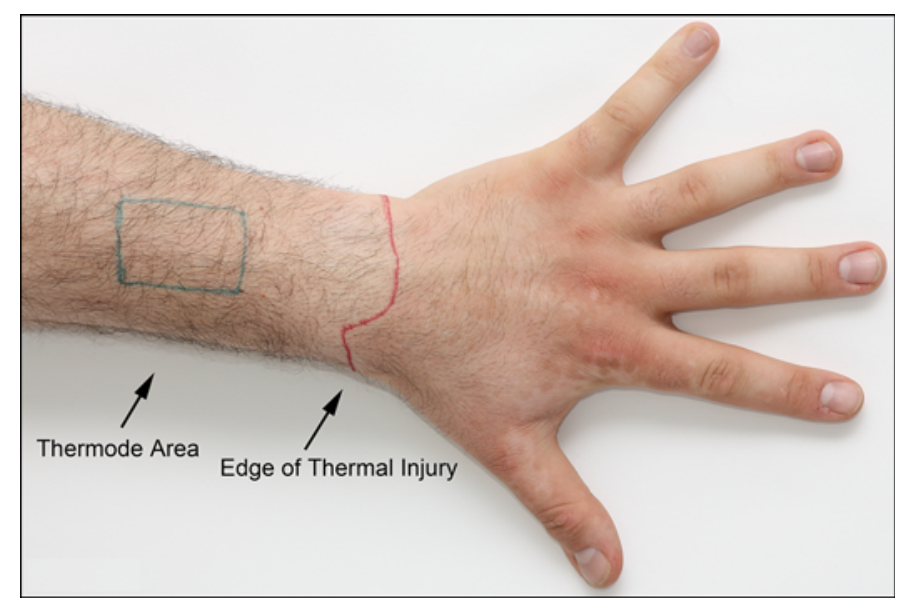

Figure 1.

Anatomic location of sensory probe for subject 1.

the injury was sustained, when pain from the burn began, how the pain changed over time, and medications tried for pain relief. The severity of the subjects' pain was also assessed using a visual analog scale (VAS); evoked pain was assessed using either a foam brush or von Frey filaments. Quantitative thermal sensory testing (QST) was evaluated at the described sites using a TSA-II NeuroSensory Analyzer (Medoc, Israel) with a $3.2 \times 3.2 \mathrm{~cm}$ Peltier device thermode that either warms or cools the skin surface. Cutoff temperatures $\left(50{ }^{\circ} \mathrm{C}\right.$ or $0{ }^{\circ} \mathrm{C}$ for warm and cold, respectively) were preset to prevent skin injury. The order in which the thermal thresholds were measured was cold detection, warm detection, cold pain detection, and heat pain detection. The holding temperature for the probe was initially set at $32{ }^{\circ} \mathrm{C}$; the temperature change for the probe occurred at a linear rate of $1^{\circ} \mathrm{C} / \mathrm{s}$. The cutoff temperature was recorded if the temperature reached the cutoff limit before the subject indicated a threshold level. The threshold was determined four times and then averaged for each thermal modality at each location [17].

\section{Statistical Analysis}

Statistical tests were performed at the $\alpha$-level of significance of 0.05 for all analyses using parametric tests, specifically Student $t$-tests. Data management and statistical analyses were performed using Microsoft Office Excel (2003; Redmond, Washington) and plotted as mean \pm standard error of the mean (SEM). All graphs show mean \pm SEM. 


\section{RESULTS}

\section{Subjects}

Of the five subjects who sustained a blistering thermal injury, one had bilateral hand injuries, two had a left hand injury, one had a right hand injury, and one had a right forearm injury. Injuries were sustained 8 weeks to 11 years prior to enrollment, and subjects rated their pain (VAS score) at the time of injury as ranging from 3 (1 subject) to 10 (4 subjects; mean of 8.6). Baseline sensory characteristics and demographics for both the injured and control subjects are shown in Table 1. All burns were well healed. Three of the subjects had no pain at the time of the study. Two subjects, who had sustained burn injuries 3.5 and 11 years previously, described mild, intermittent pain (varying from $0-1$ on the VAS) in the burned area. The eight nondisabled volunteers had no history of a blistering burn injury and were similar in age and sex to the burn injury subjects.

\section{Subject 1}

The subject is a 26 yr old male Veteran who sustained bilateral thermal injuries to his hands, which were unshielded, following a roadside bombing about $3.5 \mathrm{yr}$ prior to this study. He did not require skin grafting to either hand. He described the pain as excruciating (9/10 on a 0-10 pain scale) in the weeks following the burn injury. At the time of the injury, the subject described his pain primarily as throbbing, sharp, hot/burning, tender, and sickening, and his skin felt "tight" or like his hands were in an oven. The subject's pain improved after approximately $100 \mathrm{~d}$, and at the time of study his pain was about $0-1$ on a $0-10$ pain scale. At the time of the study, the subject noted that he was continuing to experience spontaneous tingling between his thumb and first digit (trigger(s) not known). He noted that his hands become colder "faster" than prior to the injury. At the time of the study, he was not taking any medication for pain.

\section{Subject 2}

The subject is a 36 yr old female who sustained a left hand injury approximately $10 \mathrm{yr}$ prior to this study after bumping against a hot ceramics kiln, causing an extremely painful (10/10) second-degree injury. She did not require any skin grafting. She described her pain as primarily hot/ burning with a mild component of tenderness lasting several days. At the time of the study, the subject was not experiencing any pain symptoms from her injury and was not taking any medication for pain.

\section{Subject 3}

The subject is a 56 yr old female who sustained a severe right hand thermal injury approximately 7 yr prior to this study. According to the subject, she accidentally

Table 1.

Demographics for enrolled subjects.

\begin{tabular}{|c|c|c|c|c|c|c|}
\hline Age (yr) & Sex & $\begin{array}{c}\text { Location of } \\
\text { Thermal Injury }\end{array}$ & $\begin{array}{l}\text { Time Since } \\
\text { Injury }\end{array}$ & $\begin{array}{l}\text { Average Pain at } \\
\text { Time of Injury } \\
(0-10)\end{array}$ & $\begin{array}{c}\text { Average Daily } \\
\text { Pain at Enrollment } \\
(0-10)\end{array}$ & $\begin{array}{c}\text { Allodynia at } \\
\text { Time of Testing } \\
(0-10)\end{array}$ \\
\hline \multicolumn{7}{|c|}{ Thermal Subjects } \\
\hline 26 & Male & Bilateral hands & $3.5 \mathrm{yr}$ & 10 & $0-1$ & 0 \\
\hline 36 & Female & Left hand & $10 \mathrm{yr}$ & 10 & 0 & 0 \\
\hline 56 & Female & Right hand & $7 \mathrm{yr}$ & 10 & 0 & 0 \\
\hline 53 & Male & Left hand & $11 \mathrm{yr}$ & 10 & $0-1$ & 0 \\
\hline 37 & Female & Right forearm & $8 \mathrm{wk}$ & 3 & 0 & 0 \\
\hline \multicolumn{7}{|c|}{ Control Subjects } \\
\hline 34 & Male & NA & NA & NA & 0 & 0 \\
\hline 34 & Male & NA & NA & NA & 0 & 0 \\
\hline 39 & Male & NA & NA & NA & 0 & 0 \\
\hline 49 & Male & NA & NA & NA & 0 & 0 \\
\hline 47 & Female & NA & NA & NA & 0 & 0 \\
\hline 37 & Female & NA & NA & NA & 0 & 0 \\
\hline 34 & Female & NA & NA & NA & 0 & 0 \\
\hline 31 & Female & NA & NA & NA & 0 & 0 \\
\hline
\end{tabular}


spilled hot cooking oil on her hand during a kitchen fire. She sustained primarily second- and minor third-degree burns, requiring some minor skin grafting. Initially she did not feel any pain following the injury; however, $1 \mathrm{~d}$ later she developed excruciating pain that she described as throbbing, stabbing, shooting, hot/burning, and tender. The subject was not sure how long the pain lasted, but at the time of the study did not have any pain symptoms and was not taking any medication for pain.

\section{Subject 4}

The subject is a $53 \mathrm{yr}$ old male who sustained a second-degree burn to the entire left hand about $11 \mathrm{yr}$ prior to the study. The subject was attempting to repair an oil burner in his home when it ignited and engulfed his hand in flame. He initially described the pain as 10/10. He described the pain following the injury as shooting, stabbing, sharp, and hot/burning. He was not sure when the pain began to improve, but noted that, at the time of the study, his pain was about $0-1$ on a $0-10$ pain scale. At the time of the study, he was not taking any medication for pain.

\section{Subject 5}

The subject is a $37 \mathrm{yr}$ old female who sustained a right forearm injury approximately 8 weeks prior to this study after accidentally bumping into a hot oven tray while cooking. She did not require any skin grafting. Initially, she described the injury as painful (3/10), but this only lasted about $1 \mathrm{~d}$. The pain was described as hot/ burning and gnawing. The subject did not have any pain symptoms at the time of the study and was not taking any medication for pain.

\section{Altered Pain Thresholds Following Burn Injury}

All subjects tolerated QST analysis in all three locations. The mean VAS score at the time of testing was 0 (out of 10). None of the subjects with thermal injury experienced allodynia to brush or von Frey stimulation in any of the tested areas.

The burned subjects' responses to thermal sensory thresholds are shown in Table 2. None of the five subjects showed a difference for warm detection or cold detection,

Table 2.

Sensory thresholds at three stimulation sites.

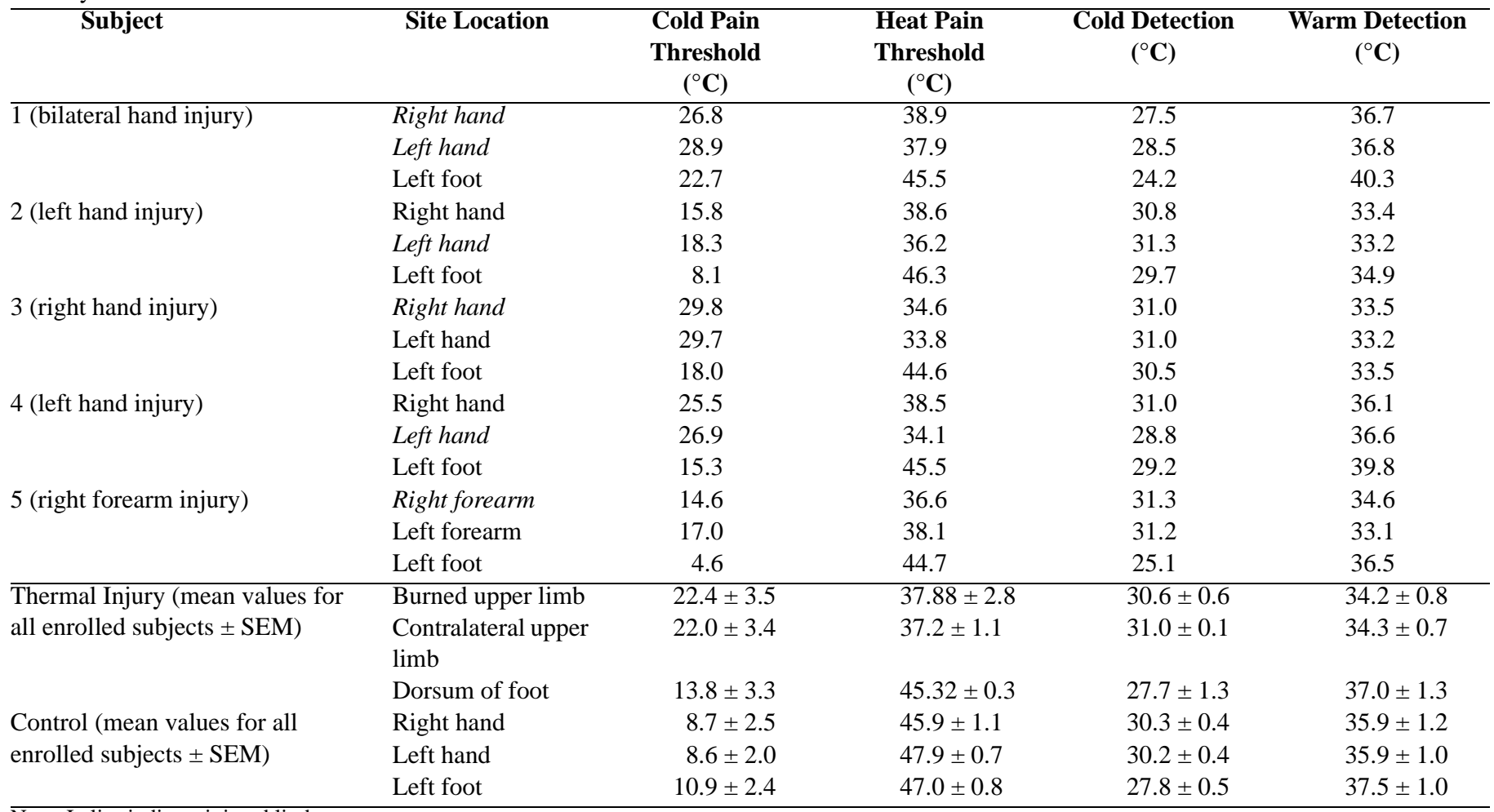

Note: Italics indicate injured limb.

SEM = standard error of mean. 
nor were the mean or median values for cold detection or warm detection statistically significant when compared with nonburned volunteers for any of the three sites (Figure 2). However, in the four subjects who sustained a unilateral thermal injury, the heat pain and cold pain thresholds in both the injured limb and the contralateral uninjured limb differed from the corresponding thresholds in the control subjects (Table 2 and Figure 2). For these subjects, the mean for heat pain threshold in the burned limb was $37.88 \pm 2.8{ }^{\circ} \mathrm{C}$ compared with $46.9 \pm 0.6{ }^{\circ} \mathrm{C}$ in the control subjects. Furthermore, the mean for cold pain threshold in the burned limb was $22.4 \pm 3.5^{\circ} \mathrm{C}$ compared with $8.6 \pm 1.5^{\circ} \mathrm{C}$ in the control subjects. The mean heat pain threshold in the contralateral (uninjured) limb was
$37.2 \pm 1.1{ }^{\circ} \mathrm{C}$, while the mean cold pain threshold in the contralateral (uninjured) limb was $22.0 \pm 3.4^{\circ} \mathrm{C}$.

The heat pain threshold from the dorsum of the foot was not different from the control population tested in any of the subjects with burn injury. However, while the mean for cold pain threshold was not statistically different for the dorsum of the foot, two of the subjects with unilateral burn injury, including one subject who described ongoing, intermittent pain at the burn site, displayed differences of $>1$ standard deviation compared with the control population (Table 2).

The subject who had sustained bilateral hand injuries and described ongoing intermittent pain in the burned areas displayed lowered pain threshold in both of his
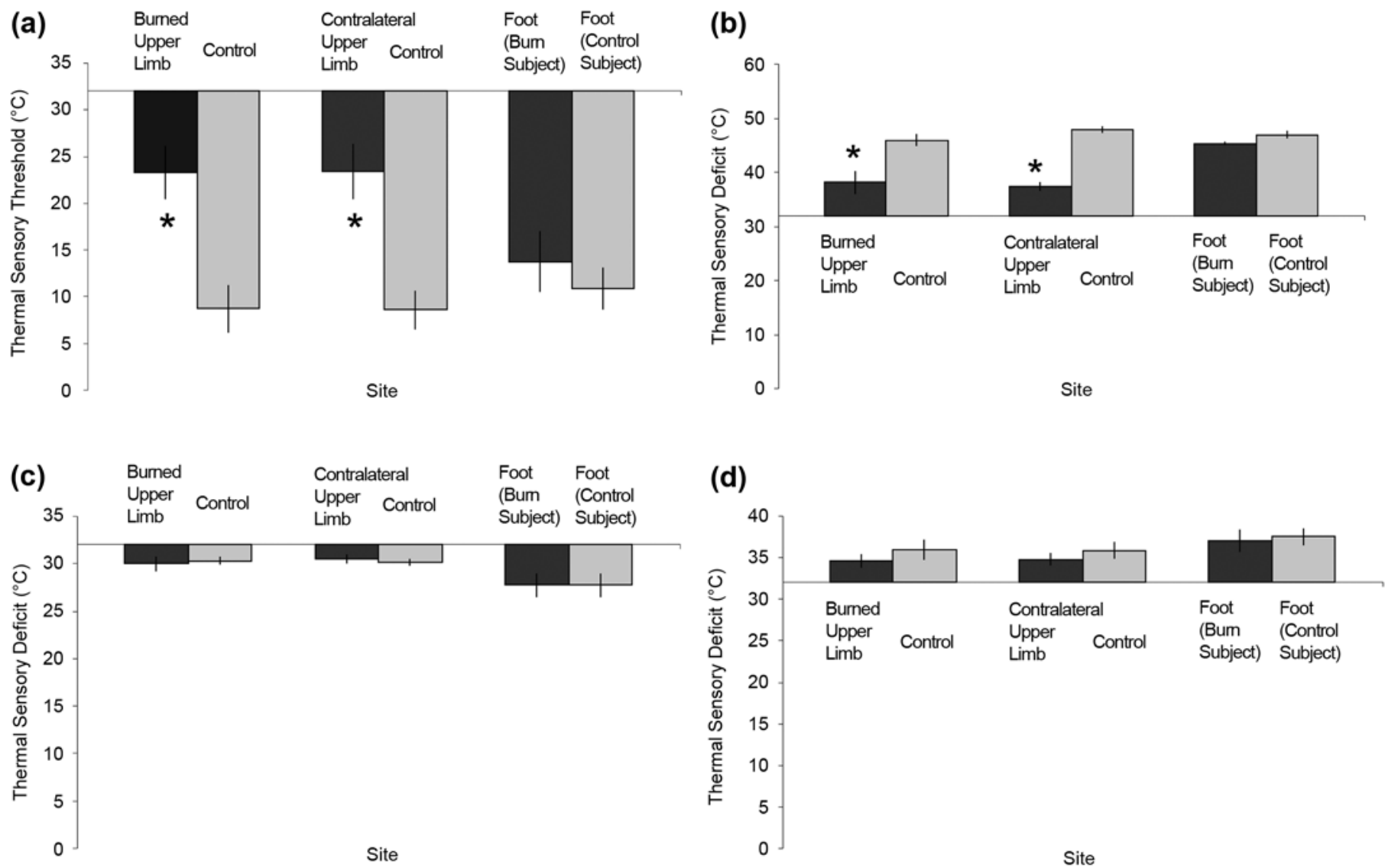

Figure 2.

Sensory thresholds are altered in injured limb and contralateral uninjured limb. When compared with corresponding sensory thresholds in nondisabled uninjured subjects, (a) cold pain threshold and (b) heat pain threshold were statistically different in both injured upper limb and contralateral uninjured upper limb. Neither (c) cold detection nor (d) warm detection showed any statistical significance when compared with uninjured subjects at any of recording locations. Graphs show mean \pm standard error of mean. ${ }^{*} p<0.05$. 
upper limbs (heat pain threshold was $38.9{ }^{\circ} \mathrm{C}$ on the right limb and $37.9^{\circ} \mathrm{C}$ on the left limb; cold pain threshold was $26.8^{\circ} \mathrm{C}$ on the right limb and $28.9{ }^{\circ} \mathrm{C}$ on the left limb), but while there was no statistical difference from the control population with respect to the heat pain thresholds derived from the dorsum of his foot, a difference was seen with respect to cold pain threshold $\left(22.7^{\circ} \mathrm{C}\right.$ in bilaterally burned patient vs $10.9 \pm 2.4$ in controls). Therefore, thresholds for heat pain and cold pain were reduced for all subjects in this cohort compared with the controls in both the burned and contralateral limb, and in three of the subjects, cold pain thresholds were also decreased in the foot.

\section{DISCUSSION}

Our observations indicate changes in pain threshold up to $11 \mathrm{yr}$ following focal burn injury of the upper limb(s), i.e., lowered threshold for warm pain and cold pain in areas outside the zone of initial injury both proximal to the healed burn in the injured limb and in the contralateral limb. Three of the five subjects also displayed lowered cold pain threshold in their unburned foot.

The presence of long-lasting extraterritorial alterations in pain thresholds in these previously burned subjects may have implications for our understanding of the mechanisms contributing to pain after thermal injury. Spread of pain to the contralateral limb after a unilateral insult suggests a systemic change, for example priming of the immune system [14], a central neuropathic mechanism [18], or spinal neuroplasticity. In response to peripheral nerve injury or peripheral inflammation, primary nociceptive neurons can become hyperexcitable so that they give rise to abnormal, high-frequency firing [19], and they may trigger central sensitization so that pain signals are generated or amplified within the central nervous system, contributing to chronic hyperalgesia and allodynia [20].

Our observations demonstrate contralateral changes in pain threshold following burn injury of the hand, with a smaller change in pain threshold in the feet in three of the five subjects studied. Our observation of contralateral reductions in pain thresholds in all subjects suggests that the changes underlying extraterritorial pain may be most prominent within spinal segments and the corresponding dermatomes located closest to the site of injury.
Animal models of neuropathic and inflammatory pain demonstrate extraterritorial allodynia [8] and in some cases contralateral pain [21] following unilateral injury. For example, mirror-image pain occurs in unilateral sciatic inflammatory neuritis [22]. In a rodent model of nerve injury using unilateral spinal root ligation, intravenous lidocaine was found to reverse ipsilateral, but not contralateral, allodynia, suggesting that different mechanisms may contribute to ipsilateral and contralateral pain following nerve injury [23]. Potential mechanisms of contralateral change that have been suggested include putative humoral and neuronal mechanisms [18] and activation of spinal microglia and proinflammatory cytokines [24]. The development of contralateral changes including gene induction in contralateral nerves but not in neighboring or remote nerves [25] suggests a spinal mechanism. Consistent with this suggestion, development of allodynia in the contralateral uninjured limb following a unilateral burn injury in rats is paralleled by development of hyperexcitability of dorsal horn neurons and activation of microglia on both sides of the spinal cord [16]; minocycline, which inhibits microglial activation, attenuates allodynia on both sides of the body in this model [26].

\section{CONCLUSIONS}

The mechanisms underlying long-lasting changes in pain threshold after burn injury in humans are not yet understood. Together with previous studies in animal models, our observations suggest the possibility that central (e.g., spinal) or systemic mechanisms can trigger long-lasting changes in pain sensitivity that can persist for years after a burn injury has healed. By understanding these mechanisms, it may be possible to target them so as to develop more effective approaches to the treatment of pain following burn injury.

\section{ACKNOWLEDGMENTS}

\section{Author Contributions:}

Study concept and design: T. Z. Fischer, S. G. Waxman.

Patient assessment: T. Z. Fischer.

Acquisition of data: T. Z. Fischer.

Drafting of manuscript: T. Z. Fischer, S. G. Waxman.

Financial Disclosures: The authors have declared that no competing of interests exist. 
Funding/Support: This material was based on work supported in part by grants from the Rehabilitation Research and Development Service and the Medical Research Service, Veterans Health Administration.

Additional Contributions: The Center for Neuroscience and Regeneration Research is a collaboration of the Paralyzed Veterans of America and the United Spinal Association with Yale University. The authors thank Dr. Betsy Schulman for administrative, technical, and material support in the preparation of this manuscript.

Institutional Review: The protocol was approved by the Human Studies Subcommittee (Department of Veterans Affairs Connecticut Healthcare System, West Haven, Connecticut) and the Institutional Review Board (Yale University, New Haven, Connecticut). Written informed consent was obtained from each study participant at the time of the testing.

Participant Follow-Up: The authors do not plan to inform participants of the publication of this study.

\section{REFERENCES}

1. Marvin J. Management of pain and anxiety. In: Carrougher GJ, editor. Burn care and therapy. St. Louis (MO): Mosby; 1998.

2. Carrougher GJ, Ptacek JT, Sharar SR, Wiechman S, Honari S, Patterson DR, Heimbach DM. Comparison of patient satisfaction and self-reports of pain in adult burn-injured patients. J Burn Care Rehabil. 2003;24(1):1-8.

[PMID:12543984]

http://dx.doi.org/10.1097/00004630-200301000-00003

3. Choinière M, Melzack R, Rondeau J, Girard N, Paquin MJ. The pain of burns: Characteristics and correlates. J Trauma. 1989;29(11):1531-39. [PMID:2585565] http://dx.doi.org/10.1097/00005373-198911000-00013

4. Choinière M, Melzack R, Papillon J. Pain and paresthesia in patients with healed burns: An exploratory study. J Pain Symptom Manage. 1991;6(7):437-44. [PMID:1940489] http://dx.doi.org/10.1016/0885-3924(91)90043-4

5. Malenfant A, Forget R, Amsel R, Papillon J, Frigon JY, Choinière $M$. Tactile, thermal and pain sensibility in burned patients with and without chronic pain and paresthesia problems. Pain. 1998;77(3):241-51. [PMID:9808349] http://dx.doi.org/10.1016/S0304-3959(98)00096-7

6. Difede J, Jaffe AB, Musngi G, Perry S, Yurt R. Determinants of pain expression in hospitalized burn patients. Pain. 1997;72(1-2):245-51. [PMID:9272809] http://dx.doi.org/10.1016/S0304-3959(97)00045-6

7. Gilboa D, Friedman M, Tsur H. The burn as a continuous traumatic stress: Implications for emotional treatment during hospitalization. J Burn Care Rehabil. 1994;15(1):8691, discussion 91-94. [PMID:8150849] http://dx.doi.org/10.1097/00004630-199401000-00017

8. Tal M, Bennett GJ. Extra-territorial pain in rats with a peripheral mononeuropathy: Mechano-hyperalgesia and mechano-allodynia in the territory of an uninjured nerve. Pain. 1994;57(3):375-82. [PMID:7936715] http://dx.doi.org/10.1016/0304-3959(94)90013-2

9. Nozaki-Taguchi N, Yaksh TL. A novel model of primary and secondary hyperalgesia after mild thermal injury in the rat. Neurosci Lett. 1998;254(1):25-28. [PMID:9780083] http://dx.doi.org/10.1016/S0304-3940(98)00648-X

10. Raja SN, Campbell JN, Meyer RA. Evidence for different mechanisms of primary and secondary hyperalgesia following heat injury to the glabrous skin. Brain. 1984;107(Pt 4):1179-88. [PMID:6509313] http://dx.doi.org/10.1093/brain/107.4.1179

11. Summer GJ, Dina OA, Levine JD. Enhanced inflammatory hyperalgesia after recovery from burn injury. Burns. 2007; 33(8):1021-26. [PMID:17707592] http://dx.doi.org/10.1016/j.burns.2007.02.007

12. Summer GJ, Puntillo KA, Miaskowski C, Dina OA, Green PG, Levine JD. TrkA and PKC-epsilon in thermal burninduced mechanical hyperalgesia in the rat. J Pain. 2006; 7(12):884-91. [PMID:17157774]

http://dx.doi.org/10.1016/j.jpain.2006.04.009

13. Summer GJ, Romero-Sandoval EA, Bogen O, Dina OA, Khasar SG, Levine JD. Proinflammatory cytokines mediating burn-injury pain. Pain. 2008;135(1-2):98-107.

[PMID:17590515] http://dx.doi.org/10.1016/j.pain.2007.05.012

14. Youn YK, LaLonde C, Demling R. The role of mediators in the response to thermal injury. World J Surg. 1992;16(1): 30-36. [PMID:1290263] http://dx.doi.org/10.1007/BF02067111

15. Sorkin L, Svensson CI, Jones-Cordero TL, Hefferan MP, Campana WM. Spinal p38 mitogen-activated protein kinase mediates allodynia induced by first-degree burn in the rat. J Neurosci Res. 2009;87(4):948-55. [PMID:18855936] http://dx.doi.org/10.1002/jnr.21905

16. Chang YW, Tan A, Saab C, Waxman S. Unilateral focal burn injury is followed by long-lasting bilateral allodynia and neuronal hyperexcitability in spinal cord dorsal horn. J Pain. 2010;11(2):119-30. [PMID:19744891] http://dx.doi.org/10.1016/j.jpain.2009.06.009

17. Petersen KL, Fields HL, Brennum J, Sandroni P, Rowbotham MC. Capsaicin evoked pain and allodynia in postherpetic neuralgia. Pain. 2000;88(2):125-33. [PMID:11050367] http://dx.doi.org/10.1016/S0304-3959(00)00311-0

18. Koltzenburg M, Wall PD, McMahon SB. Does the right side know what the left is doing? Trends Neurosci. 1999; 22(3):122-27. [PMID:10199637] http://dx.doi.org/10.1016/S0166-2236(98)01302-2

19. Devor M. The pathophysiology of damaged peripheral nerves. In: Wall PD, Melzack R, editors. Textbook of pain, 
2nd ed. Edinburgh (UK): Churchill Livingstone; 1994. p. 79-101.

20. Woolf CJ. Dissecting out mechanisms responsible for peripheral neuropathic pain: Implications for diagnosis and therapy. Life Sci. 2004;74(21):2605-10. [PMID:15041442] http://dx.doi.org/10.1016/j.lfs.2004.01.003

21. Arguis MJ, Perez J, Martínez G, Ubre M, Gomar C. Contralateral neuropathic pain following a surgical model of unilateral nerve injury in rats. Reg Anesth Pain Med. 2008; 33(3):211-16. [PMID:18433671]

22. Chacur M, Milligan ED, Gazda LS, Armstrong C, Wang H, Tracey KJ, Maier SF, Watkins LR. A new model of sciatic inflammatory neuritis (SIN): Induction of unilateral and bilateral mechanical allodynia following acute unilateral peri-sciatic immune activation in rats. Pain. 2001;94(3): 231-44. [PMID:11731060] http://dx.doi.org/10.1016/S0304-3959(01)00354-2

23. Sinnott CJ, Garfield JM, Strichartz GR. Differential efficacy of intravenous lidocaine in alleviating ipsilateral versus contralateral neuropathic pain in the rat. Pain. 1999; 80(3):521-31. [PMID:10342413] http://dx.doi.org/10.1016/S0304-3959(98)00245-0

24. Milligan ED, Twining C, Chacur M, Biedenkapp J, O’Connor K, Poole S, Tracey K, Martin D, Maier SF, Watkins LR. Spinal glia and proinflammatory cytokines mediate mirror-image neuropathic pain in rats. J Neurosci. 2003; 23(3):1026-40. [PMID:12574433]
25. Kleinschnitz C, Brinkhoff J, Sommer C, Stoll G. Contralateral cytokine gene induction after peripheral nerve lesions: Dependence on the mode of injury and NMDA receptor signaling. Brain Res Mol Brain Res. 2005;136(1-2):23-28. [PMID:15893583]

http://dx.doi.org/10.1016/j.molbrainres.2004.12.015

26. Chang YW, Waxman SG. Minocycline attenuates mechanical allodynia and central sensitization following peripheral second-degree burn injury. J Pain. 2010;11(11):1146-54. [PMID:20418178] http://dx.doi.org/10.1016/j.jpain.2010.02.010

Submitted for publication April 13, 2011. Accepted in revised form October 11, 2011.

This article and any supplementary material should be cited as follows:

Fischer TZ, Waxman SG. Extraterritorial temperature pain threshold abnormalities in subjects with healed thermal injury. J Rehabil Res Dev. 2012;49(4):515-22.

http://dx.doi.org/10.1682/JRRD.2011.04.0071

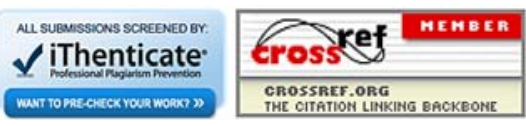

